\title{
Studying Legibility Perception and Pedestrian Place in Urban Identification
}

\author{
Golnaz Tavassolian*, Mostafa Nazari \\ Department of Architecture, Mashhad Branch, Islamic Azad University, Mashhad, Iran \\ Email address: \\ Golnaz.tavassolian@gmail.com (G. Tavassolian), Mostafa66nazari@yahoo.com (M. Nazari)
}

\section{To cite this article:}

Golnaz Tavassolian, Mostafa Nazari. Studying Legibility Perception and Pedestrian Place in Urban Identification. International Journal of Science, Technology and Society. Special Issue: Research and Practice in Architecture and Urban Studies in Developing Countries. Vol. 3, No. 2-1, 2015, pp. 112-115. doi: 10.11648/j.ijsts.s.2015030201.32

\begin{abstract}
Legibility and its effect on users of urban space have been noteworthy for many theorists in urbanization area. In a way that from their view, behavior patterns of pedestrians are severely affected by legibility perception of the body and their environment activity. The current research is to study legibility perception and pedestrian place in urban identification. In this research, there is an attempt to study collected data, based on the data collected from library search and related literature, through descriptive - analytic method is presented. This article analyzes legibility in urban space based on pedestrian view, introduces criteria for legible city, and present indices for designing streets to be used in urban space.
\end{abstract}

Keywords: Legibility, Urban Space, Perception, Identity

\section{Introduction}

Paths are as the most important structural and intellectual element in a city, coming to minds of citizens as lines connecting different points in a city. These communal spaces had various characteristics for pedestrians in the past, like legibility feature. This is while today's civil society, due to pragmatism and routine, doesn't pay too much attention to pedestrians' demands and by out of care and study constructions in urban space have the legibility quality neglected. Legibility and its effect on urban space users have been noteworthy for many theorists in urbanization filed. In a way that from their view, behavior patterns of pedestrians are severely affected by legibility perception of the body and their environment activity. One of these theorists is Kevin Lynch who by presenting the topic of image of the city introduces structural elements comprising legibility: nodes, edges, landmarks, paths, and districts [1]. On the other hand, E. Bentley in his book about responsive areas based on Lynch elements introduces guidelines to achieve legibility in urban spaces [2]. Francis Tibbalds in "Citizen-oriented Urbanization" believes that urban areas should have legibility feature and be easily comprehensible, city landmarks can play an important role in this issue [3]. Based on the conducted researches, we need more studies regarding environment legibility and its effects. Therefore, in the current research, environment legibility will be analyzed and its effect over pedestrian will also be the matter of study.

\section{Research Theoretical Foundations}

Public places are the most important parts of the city which one of them is city streets having the highest level of quality and quantity in social interactions and motions in the city. One of the principles in designing streets is its legibility [4]. In this research, there is an attempt to study collected data, based on data collected from library search and related documents, through descriptive analytic method; and ultimately conclude and present suggestions. This research analyzes legibility in urban space based on the pedestrian view and introduces criteria for a legible city, and present indices for designing streets to be used in urban space.

\section{Research History}

By legibility of a city, it is meant to easily recognize urban parts and link them together in an integrated format. From the view point of Golkar [5], legibility is an ability to easily read the environment and get to the points or addresses intended. In Michelle Trib view, legibility is a characteristic of an element that makes a clear image in the view of the observer [5]. In a city that qualifies a legible image, all the elements like 
districts, important and attractive buildings, streets and avenues can be distinguished or pictured in a joined set. An environment which is clear in mind, not only creates importance feeling but also deepen the height and level of human experience [6].

Legibility is a quality which provides requisites of perception of a place and becomes important in two levels of structure and activity. These two levels can have coverage to make best use of potential ability. This issue becomes more important for strangers as they need to quickly understand the environment without any previous introductions [2]. A city is a thorough imagination of communities on the earth. This imagination becomes clear through massive signs more or less legible for a citizen or a stranger. These signs with various degrees have concepts determining relationships among human beings and his or her land. They have a kind of symbolic role of information history and guidelines or rules or a symbol of two or several type of information like this in a uniform system of collective behavior of individuals in an environment.

Legibility in the image of a city provides a possibility that the person can easily find his location toward all points of that city. Thus, entrance of a city because of being the first point of the map in intellectual mind of strangers is of high importance; improving these index points in their minds is possible through identifiable entrance design [8]. Lynch concluded that creation of spaces with clear urban legibility should be an important attention point that in them five legibility elements including path, edge, node, district and landmark have a clear role and present more visual delight, emotional security, and human experience density [9]. Partial power and wealth of these five spatial elements give unique features and harmony to the city. Cities with strong elements, despite exhaustion and failure, might be interesting places for living [10]. Kevin Lynch states that legible city isn't an ordered city but can be ordered, while some arrangements are crucial for the stranger; there also should be a clear order, a pattern continuously perceived, the one deepening the communication [11].

\section{Theoretical Foundations}

\subsection{Perception}

Perception is a process placed in the center of any environmental behavior because the source for any data is environmental. Environments intrigue all the feelings and face the person with information more than human's capability to process. Therefore, perception isn't something like feeling, but is as the result of process filtration by the person. Perception is also the exchange between speed and precision. Speed and precision are suitable goals in intellectual process. Our mental representation make this exchange easier by quick recognition of things seem to be possible, despite sensory or visual pattern changes [12].

Recognizing the environment requires something more than recognition of elements and spaces, awareness of the way of linkage and relation between them is necessary. Therefore, to create awareness of the environment, not only mental images are needed but these images also should be in a linkage. Set of similar related images creates an intellectual model or a cognitive map from the environment. Recognition means to be familiar and have the ability to guess what the next occurrence is and what reaction is needed. Recognition means having several options to go to a place and have the possibility of finding the way without going to the start point, if you mistakenly go to another way.

Perception means the clearance of locational pattern for people. It can clear the way to use every space and place for them [14]. All legibility characteristics happen to the pedestrian by passing the mental space. Accordingly, Iltson believes that recognition of the environment is far more than merely seeing and feeling an environment; it is related to complex environmental stimuli comprising perception, emotion, implication, and worth aspect. Naghizadeh states hierarchy of the perception- intellectual perception, illusory perception, and imaginary perception-in "Analysis of Urban Spaces"; and summarizes some topics (feeling, fact and reality, implication, inference, intellect, insight, thinking, empathy, and aesthetics) [15].

Carmona point that perception isn't a biologic process, but is obtained through social and cultural relationships that their perception depending on their qualities (age, gender, nationality, life style, etc.) is different. Following legibility perception is mental image with three qualities: identity, structure, and meaning [16].

\subsection{Identity}

Schulz points to the relationship between legibility and mental image, and says that mental image and identity have a direct relationship with each other. Kurez Louis Alfred [15] states that identity is symbolic structures of cognitive collections from a society that is founded on previous generations and make today available in the hands of that society. On the other hand, Naghizadeh [16] mentions three identity elements to be considered. The first group is surface and deep identity elements of the art away from society and context; the second group includes human identity elements (creating art and society) that created that art and know that as itself; and the third group is contextual identity elements which that art is in its context and points to this fact that identity has indices like relationship with history, originality, coordination of form and performance and beliefs, unity if identity, spirituality, and familiarity and lack of being foreign.

\subsection{Structure}

In fact, spatial relationship of every element to other elements and observer is structure. Spatial structure is the product of spatial process in which space becomes organized through social, economic, and natural processes. Rogers defines spatial structure of the city considering place organization of social, economic places in urban areas; with the purpose of finding and then explaining and predicting regularities in coordination of people and urban space. The most important feature in space structure is permeability index [17]. 


\subsection{Sense}

Based on Lynch view, sense is mental role making and meaningfulness of urban places. It is the meaning of each element from the view of the observer that can be performance sense or can be emotional or personal. Carmona puts symbol and meaning next to each other because of covering, and he states that we should notice to the meaning created for people. The effect of environment over the observer is important and is put by the pedestrian mental structure of maps and its formation [11]. In 1980, Appleyard introduced four methods completing Lynch works (paths, edges, nodes, landmarks) that based on that, buildings and other natural elements are recognized by the observers; those methods include:

- With the imageability and distinction level existent in their form,

- With their visibility level while people around them are in motion,

- With their role in a building complex or in an activity,

- With the importance of that building in society.

All urban places have sense, symbol, and worth, study of symbols and their meanings is known as a typology science [18].

\subsection{Legible City}

Lynch, in a good city figure, decreases the emphasis of legibility and considers legibility as a sense of an aspect of the city. By underrating legibility importance in "Revision of City Image", he accepted that path is mostly as an issue for people. The person can always ask or consult the way on the map in case lost. He questions the importance of legible areas:

If people have a clear image of their neighborhood, then to what they are going to pay attention? Don't they enjoy through surprise or secrets? This issue highlights the topic of the difference between imageable environments and those that are favorite. Yung's study in Netherlands show that people like illegible environments; KAPLAN also noticed the need for surprise and secret [11]. Based on the conducted study, it is concluded that:

Form of the city can present various qualities that each continuously show legibility characteristics for pedestrians. These features and their appropriateness can present a good image of the city.

Qualities are realized by the observers and provide convertibility to a mental image provided that is meaningful. Several elements contribute to increase legibility and mental image and to create meaningful city form that along with familiarity with the area-because of previous attendance in the city-other measures like identity, structure, and sense can be included in this frame.

Identity including human, surface and deep identity factors can be studied. Its perception in the environment by the pedestrian presents part of legible environment.

Structures are those spatial relationships that their most important part in presenting a legible city is accessibility and permeability, providing the possibility of more attendance of pedestrian in the space that creates security in the space as the result. Legibility of an area without security is not possible.
Individuals only attend and move in the space and recognize that in existence of security.

Sense, as a general principle, can be considered in presenting a legible city because predisposes the relationship between form and performance of the pedestrian. Legibility has an extreme relation with sense. However, it should be considered that awareness of activities can be independent from form and activity patterns can create legibility, independent of structural factors, provided that activities be consistent with structural factors; this increases legibility in the space.

It should be mentioned that, a good urban space must be legible, but this legibility doesn't mean lack of visual attractions and complexities. On the other hand, a space that causes confusion and disability in navigation, is not counted as a good space. Therefore, by considering legibility for pedestrians, spaces should be designed in a way that all its elements not be evident and clear, and feeling off explore to motivate to move on be considered.

Designers should avoid designing spaces extremely cleat because it results in monotony in and lack of attachment to space. It should be noticed that spaces might not be legible for pedestrians, this is avoidable by three principles presented in this study, identity, structure, and sense. Some designing solutions are presented here for streets legibility.

Providing design solutions for walls and facades to make them coordinated and consistent to promote street legibility in pedestrian mind:

- Having a homogenous and integrated architecture in walls accompanied with clearness and legibility

- Defined appropriate edges for walls

- Having transparency over the edges and walls (appropriate perception of self interior-space and required calling to attract the addressee) [19]

- Standardization of elements and dimensions while taking care of beauty, visual, and facade appropriateness and vertical or horizontal rhythms should be organized according to common visual responsiveness.

- In view of people, the most important factor for street success are commercial attractions. This is achieved by attracting pedestrians to visit shops.

- Materials used in buildings must be compatible with the climate, tradition, and sustainability principles.

- Roof line is the main significance of perspective from all dimensions.

- Building entrances should be formed clearly and in a pre-determined way.

- Every street starts from a point and ends to another, organizing these points isn't very difficult. It is better to have such feeling in every street.

- Lighting is for vitality and liveliness during the night

- Historical monuments are identifying and enriching elements that have to be maintained [20].

\section{Discussion and Conclusion}

In the current research, legibility perception and place of pedestrian in urban identification have been studied. By 
legibility of a city, it is meant to easily recognize urban parts and also link them together in an integrated format. Following legibility perception is mental image with three qualities: identity, structure, and meaning. A good urban space should be legible-criteria that their proper, skillful, and conscious application in urban design and environment quality improvement-can provide the context for enhancing emotional-sensual and cognitive-perceptual relationship between city and its citizens; speed up the process of identifying environment legibility; and provide more measurable and responsive contexts for citizens.

\section{References}

[1] K. Lynch, "Image of the City", Persian Trans. Manouchehr Mazini, Tehran University, Tehran, 1993.

[2] E. Bentley, "Responsive Areas", Persian Trans. Mostafa Behzafar, Elm-o-Sanat University, Tehran, 2003.

[3] F. Tibbaldz, "Citizen-Oriented Urban Planning", Persian Trans. Mohammad Ahmadinezhad, Khak Publishing, Tehran, 2004.

[4] M. Bahadori, "Effective Components over Facades and Walls promoting streets legibility in cityscape", 2011.

[5] J. Pakzad, "Image of the City Lynch saw", Abadi Publishing, No. 53, 2006.

[6] K. Lynch, "Theory of Good City Image”, Persian Trans. Seyed Hasan Bahreini, Tehran University, Tehran, 1997.

[7] J. Pierre More, E. Marry Ellen, and M. Liz Sabri, "Urban spaces (Design, Implement, Manage)", Persian Trans. H. Rezaee, M. Mojabi, \& M. Rasooli, Tehran Municipality Public Relations, Tehran, 1994.

[8] M. Sashorpour, "Principles of Designing view in cities entrance", 2010.
[9] A. Madanipour, "Urban Design; Social and Spatial Approach", Persian Trans. F. Mortezaee, 2005.

[10] P. Haggette, "Geography, new combination”, Persian Trans. S. Godarzinezhad, The study and Formulation of science Books, 2000 .

[11] Carmona, M \& S. Tiesdell, "Urban Design Reader", New York, Elsevier, 2007.

[12] A. S. Mahmudi, "Urban View: Review of some theories", Abadi Quarterly, No. 53, 2006.

[13] J. Pakzad, "Theoretical Foundations and Urban Design Process", Ministry of Housing and Urban Development, Tehran, 2006.

[14] D. Bahraminezhad, "Recognition and Evaluation of Urban Space Quality in city centers: A Case Study for Shiraz City Center", Urban Design MA Dissertation, Shiraz University, 2003.

[15] L. A. Kurez, "fundamental theories of sociology", translate Farhang Ershad, Ney Publishing, Tehran, 1999.

[16] M. Naghizadeh, "Desing and Analysis of Urban Space", Jahad Daneshgahi Publishing, Tehran, 2010.

[17] Carmona, M., T. Heath, T. Oc, S. Tiesdell, "Public Places Urban Spaces", 2006.

[18] A. Eco, "Typology", Persian Trans. M. Afsari, Bokhara Bimonthly, No. 52, 2006.

[19] B. Eskandar-Afshar, M. Mahmudirad, "Design, Development, and Management of Canada Underground Spaces", Abadi Quarterly, 19th Y., No. 28, 2009.

[20] M. Behzadfar, S. Razeghi-Asl, "Main Street: Urban Design Requirements and Expectations", Abadi Quarterly, 19th Y., No. 28, 2009. 